\title{
Para além do multiculturalismo: a educação intercultural na Europa
}

Ana Lúcia Eduardo

Farah Valente

Palavras-Chave: educação intercultural, educação européia, multiculturalismo americano.
A gerais, alguns aspectos presentes na construção da proposta educativa européia que pretende superar a perspectiva do multiculturalismo americano e implementar a educação intercultural. Objetiva-se fornecer subsídios para a apreensão da singularidade do caso brasileiro, numa perspectiva comparada, bem como elementos para o debate e a problematização dos «novos mapas culturais» que vêm sendo estabelecidos, objetos da recente preocupação com a questão das diferenças culturais em estudos acadêmicos e das propostas de sua incorporação aos currículos escolares. Entretanto, as discussões não se esgotam nos estudos sobre o currículo, mas avançam para a compreensão das perspectivas metodológicas que norteiam as propostas de intervenção, uma vez que são expressões diversificadas da tentativa de dominar, na teoria e na prática, os mecanismos explícitos e implícitos que conformam a tendência à globalização inerente ao capitalismo, nesse momento de crise desencadeando manifestações reativas heterogêneas no campo políticocultural.
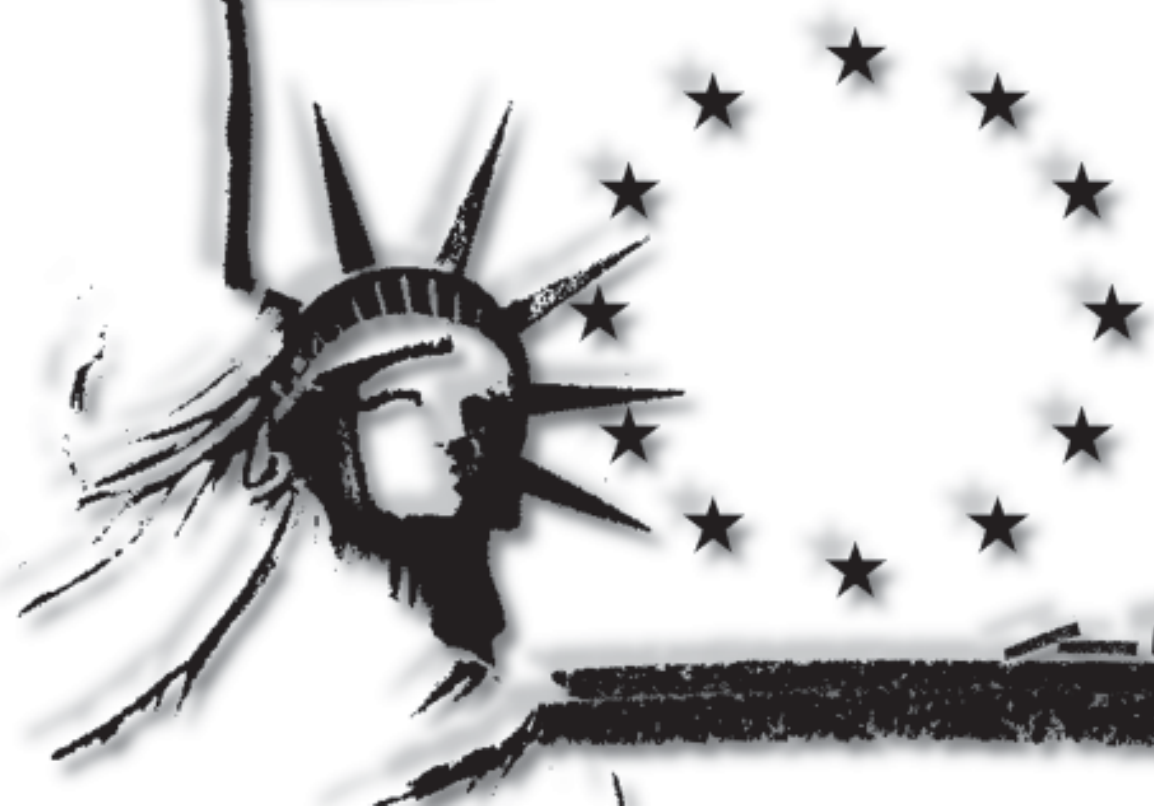
A recente preocupação com a questão das diferenças culturais em estudos acadêmicos (Popkewitz, 1992; Silva, 1995; Silva, Moreira, 1995; Dayrell, 1996; Munanga, 1996; Schwarcz, Queiroz, 1996; Santomé, 1996; Silva, Azevedo, Santos, 1996), no nosso entender, é expressão intelectual diversificada da tentativa de compreender os mecanismos explícitos e implícitos que conformam a tendência à globalização inerente ao capitalismo, nesse momento de crise desencadeando manifestações reativas heterogêneas no campo político-cultural (Valente, 1993). Perseguindo a mesma intenção, procurou-se conhecer e analisar como se organiza o campo educacional no interior da experiência mais consolidada de bloco econômico do mundo, tomando como pano de fundo a constituição da União Européia $(\mathrm{UE})^{1}$ que pressupõe o desenvolvimento de um certo nível de homogeneidade a ser construída entre os Estados-membros, desencadeando a reivindicação da diferença ou de identidades específicas que se contrapõe e que reage à homogeneização (Valente, 1996a).

Além disso, a proposta de incorporar aos currículos do ensino fundamental e médio uma parte diversificada, «exigida pelas características regionais e locais da sociedade, da cultura, da economia e da clientela», presente na LDB (Brasil, 1996, art. 26), e a organização de militantes de movimentos sociais reivindicando um espaço de expressão nos currículos escolares, como o Movimento Negro que luta pela incorporação da disciplina História da África e outras manifestações da cultura negra (Valente, 1995, 1996b), atestam para a necessidade de ser buscados caminhos para a discussão e problematização dos «novos mapas culturais» que vêm sendo estabelecidos. Entretanto, essa discussão não se esgota nos estudos sobre o currículo, mas avança para a compreensão das perspectivas metodológicas que norteiam as propostas de intervenção.

Com o objetivo de fornecer subsídios ao debate, para posterior compreensão da singularidade brasileira, em perspectiva comparada, este trabalho apresenta e comenta, em linhas gerais, alguns aspectos presentes na construção da proposta educativa européia que pretende superar a perspectiva do multiculturalismo e

implementar a educação intercultural. Nesta perspectiva, define-se «multicultural» como um conceito que se limita a constatar o estado das entidades sociais onde coabitam os grupos ou os indivíduos de culturas diferentes. $O$ «intercultural» permite a caracterização de uma dinâmica bilateral no interior da qual se engajam parceiros conscientes de sua interdependência (Leurin, 1987). É essa pretensão dos europeus que explica o título escolhido.

\section{A educação e a cultura na União Européia (UE)}

A proposta educacional para a Europa unida pretende se basear numa nova estratégia que questione os sistemas educativos nacionais, ultrapassando as fronteiras do Estado-nação. Essa concepção educativa propõe a consideração das características próprias dos países europeus e de seu caráter pluricultural.

Os textos do Tratado da UE apresentam um caráter vago bastante esclarecedor, em matéria de educação e cultura.

No artigo 126 do Tratado, após ser definida a intenção de a UE contribuir «para o desenvolvimento de uma educação de qualidade", são enumerados os seguintes objetivos:

\begin{abstract}
- desenvolver a dimensão européia na educação, nomeadamente através da aprendizagem e divulgação das línguas dos Estados-membros;

- incentivar a mobilidade dos estudantes e dos professores, nomeadamente através do incentivo ao reconhecimento acadêmico e diplomas e períodos de estudo;

- promover a cooperação entre estabelecimentos de ensino;

- desenvolver o intercâmbio de informações e experiências sobre questões comuns aos sistemas educativos dos Estados-membros;

- incentivar o desenvolvimento do intercâmbio de jovens e animadores socioeducativos;

- estimular o desenvolvimento da educação a distância. (União Européia, 1993, p. 256).
\end{abstract}

$\mathrm{O}$ artigo 128 define que a UE «contribuirá para o desenvolvimento das culturas

\footnotetext{
${ }^{1}$ A partir de 1992 essa é a denominação atual que substituiu as anteriores Comunidade Econômica Européia (CEE) e Comunidade Européia (CE).
} 
dos Estados-membros, respeitando a sua diversidade nacional e regional, e pondo simultaneamente em evidência o patrimônio cultural comum». No título cultura, de que trata esse artigo, objetiva-se incentivar a cooperação entre Estadosmembros, nos seguintes domínios:

- melhoria do conhecimento e da divulgação da cultura e da história dos povos europeus;

- conservação e salvaguarda do patrimônio cultural de importância européia;

- intercâmbios culturais não-comerciais;

- criação artística e literária, incluindo o setor audiovisual» (União Européia, 1993, p. 261).

Pode-se considerar que esses textos se valem de uma linguagem "despolitizada", como o mito nas sociedades modernas, de acordo com a proposição de Barthes (1982, p. 163-164):

O mito não nega as coisas; a sua função é, pelo contrário, falar delas; simplesmente, purifica-as, inocenta-as, fundamenta-as em natureza e em eternidade, dá-lhes uma clareza, não de explicação, mas de constatação(...) Passando da história à natureza, o mito faz uma economia: abole a complexidade dos atos humanos, confere-lhes a simplicidade das essências, suprime toda e qualquer dialética, qualquer elevação para lá do visível imediato, organiza um mundo sem contradições, porque sem profundeza, um mundo plano que se ostenta em sua evidência, cria uma clareza feliz: as coisas parecem significar sozinhas, por elas próprias.

A mitificação da linguagem, a «clareza feliz» do discurso, parece ser um recurso amplamente utilizado pela UE, como tática para aliviar tensões, neutralizar as contradições, conter polêmicas para garantir o consenso entre Estados-membros, ao menos aparentemente.

Mesmo no plano deliberativo, quando as posições da UE deveriam tornar-se explícitas de maneira a nortear as ações dos Estados-membros, o mesmo recurso mítico é utilizado ou permite-se que a linguagem empregada seja suficientemente ambígua para comportar inúmeras inter- pretações, supostamente não-contraditórias. Isso parece evidente no texto da Diretiva 77/486/CEE:

DIRETIVA DO CONSELHO de 25 de julho de 1977 ,

que tem por objetivo a escolarização dos filhos dos trabalhadores migrantes 77/486/CEE.

\section{O CONSELHO DAS COMUNIDADES EU- ROPÉIAS,}

Tendo em conta o Tratado que institui a Comunidade Econômica Européia e, nomeadamente o seu artigo 49,

Tendo em conta a proposta da Comissão, Tendo em conta o parecer do Parlamento Europeu,

Tendo em conta o parecer do Comitê Econômico e Social,

Considerando que, na sua Resolução de 21 de janeiro de 1974 relativa a um programa de ação social, o Conselho adotou, entre as ações a desenvolver prioritariamente, as que têm por objetivo melhorar as condições da livre circulação dos trabalhadores relacionadas especialmente com o acolhimento e o ensino dos seus filhos;

Considerando que, a fim de permitir a integração desses menores no meio escolar ou no sistema de formação do Estado de acolhimento, convém que estes possam dispor de um ensino adequado que inclua o ensino da língua do Estado de acolhimento;

Considerando que é igualmente necessário que os Estados-membros de acoIhimento tomem, em cooperação com os Estados-membros de origem, as medidas adequadas tendo em vista promover o ensino da língua materna e da cultura do país de origem das referidas crianças, a fim de facilitar nomeadamente a sua eventual reintegração no Estado-membro de origem,

ADOTOU A PRESENTE DIRETIVA:

Artigo $1^{\circ}$ - A presente diretiva aplica-se aos menores sujeitos à escolarização obrigatória, tal como definida pela legislação do Estado de acolhimento, que estejam a cargo de qualquer trabalhador nacional de um outro Estado-membro, que residam no território do Estado-membro em que esse nacional exerce ou exerceu uma atividade assalariada. 
Artigo $2^{\circ}$ - Os Estados-membros tomarão, em conformidade com a sua situação nacional e com o seu sistema jurídi$\mathrm{co}$, as medidas adequadas a fim de que no seu território seja proporcionado, aos menores referidos no artigo $1^{\circ}$, um ensino de acolhimento gratuito que inclua, nomeadamente, o ensino, adaptado às necessidades específicas desses menores, da língua oficial ou de uma das línguas oficiais do Estado de acolhimento.

Os Estados-membros tomarão as medidas necessárias para a formação inicial e contínua dos docentes que assegurem este ensino.

Artigo $3^{\circ}$ - Os Estados-membros tomarão, em conformidade com a sua situação nacional e com o seu sistema jurídico, e em cooperação com os Estados de origem, as medidas adequadas tendo em vista promover, em coordenação com o ensino normal, um ensino da língua materna e da cultura do país de origem em favor dos menores referidos no artigo $1^{\circ}$. Artigo $4^{\circ}$ - Os Estados-membros tomarão as medidas necessárias para dar cumprimento à presente diretiva no prazo de quatro anos a contar da sua notificação. Desse fato informarão imediatamente à Comissão.

Além disso os Estados-membros informarão à Comissão de quaisquer disposições legislativas regulares e administrativas que adotem no domínio regulado pela presente diretiva.

Artigo $5^{\circ}$ - No prazo de cinco anos, a contar da notificação da presente diretiva e, posteriormente, com a regularidade requerida pela Comissão, os Estadosmembros transmitirão à Comissão todas as informações úteis a fim de permitir apresentar um relatório ao Conselho sobre a aplicação da presente diretiva.

Artigo $6^{\circ}$ - Os Estados-membros são destinatários da presente diretiva.

(Journal Officiel des Communautés Européennes, 6/8/77, p. 32-33)

Conforme se depreende do texto, a diretiva 77/486/CEE, que tem por objetivo a escolarização dos filhos dos trabalhadores migrantes, entrou em vigor a partir de sua notificação, em agosto de 1977, prevendo que todas as medidas necessárias para seu cumprimento devessem ser adotadas no prazo de quatro anos, ou seja, até 1981 e que todos os Estados-membros devessem fornecer as informações referentes à sua aplicação à Comissão em 1982. Definidas as considerações de ordem geral e o público-alvo, são três as proposições básicas da diretiva: 1) ensino gratuito que enfatize o aprendizado da língua oficial do país de acolhimento «adaptado às necessidades específicas desses menores"; 2) formação de professores para atender à demanda; 3) ensino da língua e cultura do país de origem.

Tomemos a última proposição da diretiva como foco de nossa atenção. Uma primeira tentativa de interpretação indica que, ali, o conceito de cultura parece confundir-se com o conceito de língua e, o mais complicado, é reificado. A cultura aparece como uma "coisa»e, como tal, desprovida de qualquer dinamismo, imune ao processo de transformação, a não ser se for considerada a mobilidade conferida às relações comerciais. Ou seja, a cultura é tomada como uma mercadoria.

À luz das considerações gerais, essa proposição sugere, ainda, três razões não excludentes que poderiam justificá-la. Em primeiro lugar, uma motivação «protecionista» da língua e cultura do público-alvo constituído por filhos de trabalhadores migrantes. Nesse caso, seriam desconsideradas as relações de poder que atravessam as relações desses trabalhadores migrantes com a população do país hospedeiro. Levada às últimas conseqüências, essa justificativa implicaria a admissão da inferioridade dessas crianças ante as crianças nacionais. Uma segunda motivação «assimilacionista» apontaria para o caráter antropofágico da cultura dominante. Dessa maneira, deveriam ser encontrados meios para integrar as crianças estrangeiras ao país hospedeiro, à sua língua e à sua cultura, mesmo que isso exigisse, momentaneamente, o ensino da língua e cultura dominadas. Uma última razão poderia assumir um caráter «segregacionista» ou seja, uma resposta ao quadro de desestabilização da economia européia que promoveu a rearticulação de procedimentos xenófobos e de racismo e que, em seu viés radical defende a expulsão dos estrangeiros. $O$ aprendizado da língua e cultura de origem nada mais seria do que uma preparação para o retorno, à medida que se prevê a « reintegração» dos filhos de imigrantes ao Estados-membros de origem. 


\section{0 contexto histórico de definição da diretiva}

Se não é permitido, através de uma primeira leitura, precisar as razões da diretiva, o mesmo não se pode dizer dos propósitos não manifestos da Comissão Européia ou do contexto histórico que a provocou.

Segundo informações de um tecnocrata que trabalhou junto à Comissão por mais de dez anos e ainda hoje faz parte do quadro de funcionários da UE, a diretiva 77/486/CEE obteve como saldo político o alargamento dos poderes daquela instituição comunitária. Até aquele momento, a Comissão vinha apenas tratando de questões diretamente relacionadas à economia dos países-membros. $\mathrm{A}$ proposta contida na diretiva, tendo como subterfúgio a melhoria da livre circulação dos trabalhadores, permitiu que se atingisse um campo estratégico das políticas nacionais: o campo educacional. ${ }^{2} \mathrm{~A}$ estratégia que, segundo o informante, foi engenhosamente montada, assegurou ao seu proponente o desenvolvimento de concepções na área de sua formação e domínio o que, entre outras coisas, permitiu-lhe atingir uma posição política de destaque no organismo supranacional.

Porém, pode-se considerar que tal proposta, datada de 1975, quando foi iniciado o procedimento de decisão, ${ }^{3}$ não seria tão facilmente acatada, dado o caráter estratégico da educação, se não fosse a situação da crise que se abateu sobre os Estados-membros e que marcou o fim dos «anos dourados». Segundo Hobsbawn (1995, p. 253), esse foi um dos nomes dados pelos observadores, especialmente pelos economistas à fase excepcional da história do capitalismo desenvolvido, iniciada nos anos 50 . Contudo, «depois que passou o grande boom, nos perturbados anos 70 , à espera dos traumáticos $80(.$. O dourado fulgiu com mais brilho contra 0 pano de fundo baço e escuro das posteriores Décadas de Crise».

O boom mundial assentou-se na adoção pelas indústrias da Europa, do modelo de produção de massa fordista que, nos EUA, já era estendido para novos tipos de produção. Assim, bens e serviços restritos às minorias passavam a ser consumidos em massa. A Era de Ouro baseou-se na pesquisa científica avançada que, no campo industrial e mesmo agrícola, ultrapassava a tecnologia do século XIX. No entanto, foram fundamentais para a conformação dessa época a reestruturação do capitalismo e o avanço da internacionalização da economia, numa «espécie de casamento entre liberalismo econômico e democracia social» (idem, p. 265). O pós-guerra descartara um retorno ao laissez-faire e os objetivos propriamente políticos, como o pleno emprego, a modernização das economias atrasadas, em declínio ou arruinadas, e a contenção do comunismo passaram a ser prioridades e a justificar a forte presença governamental.

Para Hobsbawn (idem, p. 271), «o grande boom da Era de Ouro foi alimentado não apenas pela mão-de-obra dos ex-desempregados, mas por vastos fluxos de migração interna - do campo para a cidade, da agricultura (...), de regiões mais pobres para outras mais ricas». Porém, mesmo num período de crescimento econômico e de falta de mão-de-obra, os governos resistiram à livre imigração. Segundo o autor, «só se concedia a esses imigrantes, a maioria vinda dos países menos desenvolvidos do Mediterrâneo, permanência condicional e temporária, para que pudessem ser facilmente repatriados, embora a expansão da Comunidade Econômica Européia, passando inclusive [a integrá-la] vários países de imigrantes (Itália, Espanha, Portugal, Grécia), tornasse isso mais difícil».

Em que pese os limites impostos aos processos de imigração, estima-se que no início de 1970, cerca de 7,5 milhões haviam migrado para os países desenvolvidos da Europa. Essa questão, politicamente delicada, passa a ser motivo de especial preocupação desses países a partir de 1974, quando se instaura a crise.

Na verdade, é sobre essa questão que trata a diretiva 77/486/CEE. Questão espinhosa, que obteve o respaldo dos paísesmembros à época, talvez com a perspectiva de que soluções conjuntas fossem tomadas ante o problema comum.

Tudo indica que, considerando o contexto histórico de aprovação da diretiva, grande parte das expectativas dos governantes dos países-membros da UE era de que a questão da imigração fosse resolvida da maneira mais rápida possível. Mes- 
mo que aparentemente as razões de sua preocupação pudessem ser humanitárias, o ensino da língua e cultura de origem passou a ser visto como um meio de mandar o «problema» para sua casa. Livrar-se dele era a intenção. Não é por acaso que a idéia de reintegração ao Estado-membro de origem dos filhos dos trabalhadores imigrantes é destacada nas considerações iniciais da diretiva em questão. A outra opção possível seria a integração definitiva ao Estado hospedeiro, com a assimilação total dessas crianças. Mas o quadro histórico que acabamos de apresentar parece descartar essa segunda opção como a preferencial.

Contudo, a expectativa de que os imigrantes voltassem ao seu país de origem foi logo contrariada: a população estrangeira nos países hospedeiros não estava disposta a retornar. Afinal, a crise que passava a atingir os países europeus mais desenvolvidos certamente provocaria efeitos piores nos países mais pobres. Era aconselhável ficar, mesmo que a idéia de regresso à terra natal permanecesse como um sonho para os imigrantes. Um sonho que também poderia gerar divisas ao país hospedeiro, com a poupança e transações monetárias envolvidas na perspectiva do retorno ao país de origem.

Mesmo que a proposição da diretiva faça parte de uma estratégia de alargamento dos poderes da Comissão da UE e de busca de soluções ao problema da imigração em tempos de crise pelos países-membros, outros organismos internacionais passavam a engajar-se nessa discussão. Constatada a presença de uma população culturalmente diferenciada era preciso investir na busca de soluções que propiciassem uma convivência harmônica. Era preciso investir no que foi chamado de «educação intercultural».

\section{Brevíssimo histórico dos estudos sobre a educação intercultural}

O que vem sendo chamado de educação intercultural na Europa ou os estudos interculturais em ciências sociais tomaram impulso a partir dos anos 60, no momento em que, nos Estados Unidos, dois campos do conhecimento se aproximaram: Educação e Antropologia. Segundo Mauviel (1985, p. 3), por volta da década de 70 , quando os americanos definiam as grandes linhas do multiculturalismo em educação, a reflexão francesa nesse domínio era praticamente inexistente. Para o autor, dificuldades epistemológicas ou teórico-ideológicas teriam impedido a presença da França no debate internacional das pesquisas interculturais. Verbundt (1989, p. 137) resume o significado dessas dificuldades, afirmando que os franceses, temerosos de que a sociedade multiétnica enfraqueça a nação, têm feito do conceito «etnia» objeto de uma desconfiança particular. A revalorização do sentimento de pertencer ao grupo religioso, regional ou cultural vai ao encontro de uma tradição francesa enraizada não apenas no centralismo administrativo e político, mas igualmente na ideologia da Revolução de 1789. Todavia, como lembra o autor, hoje se considera necessário questionar essas tradições e buscar responder se a existência de estrutura sobre uma base étnica é obrigatoriamente um retorno ao passado.

Considerando o contexto da produção científica norte-americana no campo da Antropologia, marcada por uma tradição denominada culturalista, torna-se mais fácil compreender as bases teóricas das propostas voltadas para a educação intercultural. Em linhas gerais, tal corrente de pensamento representou um avanço em relação às perspectivas etnocêntricas e evolucionistas do início do século. No entanto, ao propor a análise de aspectos da cultura de sociedades diferentes do modelo ocidental, segundo sua lógica interna que seriam, então, relativos ao seu modo de funcionamento, seus defensores muitas vezes incorreram nos mesmos equívocos que pretendiam superar. Isso porque, logo se percebeu que o «relativismo cultural» não apenas eliminava a possibilidade de qualquer estudo comparativo, como eliminava a possibilidade de qualquer mudança cultural nas sociedades pesquisadas, imobilizadas em certos modelos ou padrões construídos pelos pesquisadores que, no limite, justificavam o tratamento diferenciado, dominador e paternalista das sociedades «avançadas».

A perspectiva culturalista, que inspira os estudos franceses sobre o intercultural que são fontes da reflexão em países de língua francesa e na Europa em geral, evidencia-se na noção de cultura proposta por 
Camilleri (1989, p. 27), psicólogo estudioso da questão. Para ele, a cultura é o conjunto de significações adquiridas, as mais persistentes e mais partilhadas que os membros de um grupo, por sua filiação a este grupo, são conduzidos a distribuir de maneira determinante sobre os estímulos provenientes de seu meio e deles mesmos, induzindo atitudes, representações e comportamentos comuns valorizados, que tendem a assegurar a reprodução por vias não-genéticas. ${ }^{4}$

Também os estudos de CohenEmerique (1989, p. 105-106), que propõem a formação em comunicação intercultural dos profissionais que trabalham junto à população estrangeira, são tomados como base de reflexão da questão intercultural européia. A psicóloga francesa acredita que no trabalho desses profissionais se tende a proceder de maneira a colocar em risco qualquer possibilidade de compreensão aprofundada do «outro». Segundo ela, interpretando se classifica, se categoriza quase imediatamente em função de seu pressuposto, eliminando, assim, a coleta de outros dados que não entram na elaboração de seu sistema explicativo, excluindo automaticamente a possibilidade de construção de outras hipóteses de explicação de condutas. Desse modo, interpretando a fala de uma pessoa de outra cultura a partir de nossos códigos, tudo se passa como se a língua francesa, tal como é usada pelo migrante ou seu intérprete, de um ponto de vista instrumental para comunicar com a sociedade de acolhida, seja portadora dos mesmos significados culturais que aqueles dos profissionais que lhes escutam, quer dizer, com o mesmo valor expressivo. Por isso, seria preciso que esses profissionais procedessem como o antropólogo, quando, em face de uma sociedade diferente da sua que pretende investigar, usa um procedimento que implica três fases: 1 ) descentralizar-se para tomar consciência de seus próprios quadros de referência e valores; 2) compreender o sistema do outro, sua cultura, reconhecendo o seu valor e 3 ) negociar, tendo em vista construir uma plataforma comum (Cohen-Emerique, 1994).

Gaudier (1990, p. 34), antropólogo belga, é bastante enfático quando critica essa fonte de inspiração teórica culturalista. Segundo esse autor, a ideologia interculturalista que reclama o apoio da Antropologia para se justificar, na realidade é absurda ao olhar dessa última. Segundo o autor, dois episódios da história da Antropologia seriam suficientes para demonstrar essa assertiva. Um deles diz respeito ao momento «culturalista» da Antropologia americana, desenvolvida entre os anos 30 55, ultrapassada e mesmo renegada por seus principais representantes. No entanto, ela sobreviveu no interior de disciplina com vocação explicitamente comercial - a «comunicação intercultural» - nos Estados Unidos. Seus esquemas foram divulgados na Europa a partir dos anos 70, graças ao sucesso das obras de E.T. Hall. O outro episódio lembra o compromisso conceitual e auxiliar da velha etnografia colonial com a dominação metropolitana. Ao definir uma etnia por sua cultura e esta pelo fato de que caracteriza uma etnia, a ideologia interculturalista pretende reabilitar o «indígena», a partir de um retrato que constrói dele. Essa imagem imutável serve ao controle e à dominação.

Contudo, embora a inspiração culturalista seja evidente nos estudos franceses, tudo indica que não apenas se procurou evitar a reprodução dos mesmos problemas apontados pela crítica, como se procurou incorporar novas reflexões, como aquelas de Barth (1995), que parecem avançar na perspectiva de compreensão da diversidade cultural.

Martine Abdallah-Pretceille (1985, 1989), no conjunto de seus trabalhos, insiste sobre a idéia de que a educação intercultural deva evitar as armadilhas do relativismo absoluto. A educadora parece preocupar-se com a panacéia que se tornaram as propostas da escola em face do desafio do pluralismo e com os riscos de um certo ativismo que, promovendo atividades interculturais no quadro da escolarização dos filhos de migrantes, nem sempre fizeram um uso conseqüente das idéias norteadoras da interculturalidade, procurando reduzir a instituição a uma nova Torre de Babel, aumentando os quadros disciplinares de referência e subdividindo o público escolar em subgrupos específicos. Para a pesquisadora, não são as culturas, nem mesmo as relações entre grupos e indivíduos pertencentes a culturas diferentes que constituem a noção de «intercultural», mas a maneira como a análise leva em con- 
ta o parâmetro cultural com todas as incidências teóricas, epistemológicas e metodológicas que interferem especialmente as perspectivas subjetivista, interacionista e situacional.

Verne (1987, p. 29-31) distingue o desenvolvimento da educação multicultural em três fases. Na primeira fase, a preocupação estaria centrada no ensino intensivo da língua oficial às crianças que empregavam uma outra língua junto às suas famílias, com o intuito de compensar suas deficiências lingüísticas. A segunda fase caracterizar-se-ia pelo ensino bilíngüe, quando também a língua materna das crianças estrangeiras passa a merecer atenção, tendo por justificativa pedagógica que o domínio da língua oficial passaria pelo aprendizado da língua materna. Nessa fase, três rupturas são produzidas. Uma, refere-se ao ensino bilíngüe num quadro pedagógico e social dominante; outra, à manutenção ou promoção das diferenças em nome dos valores culturais próprios a cada grupo social, capaz de conduzir à afirmação e desenvolvimento da identidade cultural e, a terceira ruptura conduziria à reivindicação da autonomia cultural, quer a partir da coexistência multilíngüe, quer com o objetivo de combater a cultura dominante. Por fim, na terceira fase, a promoção dos valores culturais próprios a cada grupo social passa a ser responsabilidade do conjunto dos grupos sociais, cabendo a cada grupo minoritário ou não se iniciar na cultura do outro. A diversidade cultural torna-se parte integrante do currículo escolar sob o nome de educação intercultural.

Esse pequeno histórico é ilustrativo do distanciamento progressivo que foi sendo operado entre teoria e prática da educação intercultural e dos riscos de banalização sugeridos por alguns autores e por nós corroborado.

Segundo Liauzu (1989), a bibliografia francesa sobre a questão intercultural não é apenas abundante como difícil de se dominar à medida que é constituído um campo de estudo em função de interrogações de origens múltiplas e não a partir de uma ciência social constituída. Do mesmo modo, zonas de sombra e uma explosão de problemáticas resultam das distorções entre empirismo e miséria teórica, entre demandas dos poderes e necessidades sociais, do hiato nas pesquisas sobre imigração, sobre as sociedades de origem e sobre a França.
$\mathrm{Na}$ mesma linha de reflexão crítica, Françoise Henry-Lorcerie (1989) afirma que a literatura sobre a escola e a imigração é uma literatura de caráter militante, produzida por pessoas engajadas em experiências de escolarização dos filhos de imigrantes e dirigida àqueles que estão convencidos de sua necessidade. A ausência de pesquisas científicas sobre $o$ assunto poderia ser explicada pelo fato de a escola, enquanto meio social, não ter sido alvo privilegiado de estudo - a não ser as análises da sociologia da reprodução de base marxista que nada de novo poderiam dizer sobre o assunto senão confirmar as correlações estabelecidas entre a estratificação social das famílias e a posição escolar das crianças imigrantes - e pela dificuldade de dirigir um olhar crítico distanciado sobre essa questão no contexto francês atual. Outra dificuldade seria a consideração de que a causa da militância é justa, apesar da fragilidade tateante de sua prática e das solicitações feitas por diversos protagonistas sob a forma de julgamentos e recomendações.

Para Mauviel (1985, p. 11), uma das dificuldades mais agudas da educação intercultural reside no fato de que os educadores colocam a carroça na frente dos bois e supõem que um certo número de problemas é resolvido se a cultura que pertencemos é conhecida. Ou, como afirma Camilleri-em correspondência pessoal datada de dezembro de 1995 -, embora a interculturalidade diga respeito a domínios diferentes, desde a vida social até a escola, e seja um tema que se imporá cada vez mais com os contatos crescentes e obrigatórios entre as sociedades, é, nesse momento, muito restrita aos problemas da migração. De outra parte, do ponto de vista das instituições, há ainda muitos contrasensos que devem ser corrigidos e declarações de princípio que não têm nenhuma aplicação.

A leitura de textos e artigos dedicados ao tema, especialmente os de origem francesa, nos conduz à conclusão de que a educação intercultural se constitui um campo de estudo no qual não se alcançou consenso por ser informado por perspectivas teórico-metodológicas diferentes e divergentes e pelas razões apontadas por Camilleri. Há, contudo, uma perspectiva norteadora dominante que considera o ter- 
reno do intercultural despojado de contradições e conflitos. Prenhes de boas intenções, todas as propostas nessa direção são também carregadas de ingenuidade militante e, na grande maioria dos casos, expostas à manipulação conseqüente daqueles que querem despolitizar a cultura e toda a vida social. Nesse sentido, tais propostas escorregam na lógica que paradoxalmente pretendem combater.

Por essa razão, consideramos falaciosa a proposta de uma educação intercultural como sinônima de uma educação harmônica de respeito às diferenças. $\mathrm{Na}$ verdade, trata-se de propor uma conotação nova e positiva ao fenômeno das relações entre as culturas que sempre esteve marcada pelo signo da dominação. Negar a existência de forças sociais que se impõem ante o desejo de construção de uma "sociedade feliz» não basta para transformá-la. De maneira recorrente, os textos escritos, a propósito da educação intercultural, deixam de considerar de qual sociedade estamos falando. Porém, o uso amplo e generalizado do termo «intercultural» e derivados entre as pessoas envolvidas com a questão na Europa praticamente exige que seja empregado, mas a ele associando uma perspectiva de compreensão mais crítica.

\section{A preocupação européia com a educação intercultural}

Como foi dito, não apenas a UE passou a se preocupar com a educação dos filhos de trabalhadores migrantes. O Conselho da Europa, ${ }^{5}$ outro organismo internacional, mostrou-se particularmente sensível às propostas voltadas para os problemas da imigração. Nessa mesma época, por volta de 1976, ainda não se falava em educação intercultural, mas o problema da imigração começava a preocupar as autoridades no Conselho da Europa. Uma publicação datada de 1983 merece atenção por relatar experiências levadas a cabo em vários países como Alemanha, ropéia criada em 1949, reunindo 32 Estados da Europa e que estabeleceu em 1950 a Convenção européia de salvaguarda dos direitos do homem e das liberdades fundamentais. Suécia, Inglaterra, França, Suíça, Holanda.

Como esclarece Micheline Rey, na introdução desse trabalho, a pedagogia intercultural não se propõe a substituir as tarefas fundamentais do ensino na escola, mas a alargar as preocupações existentes, insistindo sobre a influência que exercem as culturas do país hospedeiro de origem dos migrantes, umas sobre as outras. Desse modo, ela não diz respeito apenas às crianças estrangeiras e à sua capacidade de enfrentar a sua situação de vida diferente, mas também às crianças autóctones e à sua capacidade de tirar proveito da realidade pluricultural, ou seja, diz respeito ao vivido concreto de todas as crianças. Por isso, a pedagogia intercultural não é uma disciplina escolar entre outras, mas, antes, o princípio fundamental que subentende toda a atividade escolar, exigindo que a instituição escolar reexamine, revise e alargue suas próprias normas e que as atividades interculturais ultrapassem o quadro estreito da escola, assegurando o estabelecimento de relações duráveis entre alunos, capazes de resistir aos conflitos culturais entre sistemas de valores diferentes.

A leitura de cada experiência logo nos leva a refletir sobre o fato de que as situações locais relatadas são diversas, e por isso reclamam um tratamento diferenciado. Cada proposta é uma aproximação do que poderia ser chamado de prática intercultural e, nem sempre, respeitam o pressuposto geral de que todas as crianças deveriam ser o público-alvo ou que o processo cultural implica dinamismo, transformação, reinterpretações. O que as experiências relatadas acabam por evidenciar é uma preocupação centrada na diferença do «outro» e vários deslizes que enfatizam os aspectos mais superficiais e folclóricos da «cultura dos migrantes».

Assim, também aí se percebe um descompasso entre as linhas mestras da pedagogia intercultural e sua prática, o que não é de todo condenável, haja vista o terreno plural e escorregadio no qual se pretende atuar. Essa mesma impressão confirma-se no texto conclusivo quando é reivindicado o «caráter dialético» do interculturalismo, justamente baseando-se nessa multiplicidade de experiências criadas em função dos contextos a partir de um mesmo princípio e de um mesmo objetivo, como meio através do qual a instituição escolar pode atingir melhor os seus objetivos de democratização, igualdade de chances e desenvolvimento cultural. Além disso, é reclamado o reconhecimento recíproco das culturas de origem e de acolhida que não deve ocultar o fato de que, na rea- 
lidade, as culturas dos países hospedeiros estão numa relação de dominação em relação às expressões culturais dos migrantes.

No nosso entender, como já dissemos, é justamente este o aspecto que acaba por ser mascarado: as relações de poder e dominação entre os grupos em contato, o que impede a percepção de seu caráter contraditório. No plano discursivo reinvidica-se, algumas poucas vezes, essa análise mais abrangente da questão, sem que isso consiga influenciar as práticas levadas a cabo. Entretanto, essa situação de discordância entre discurso e prática pode ser explicada pela lógica societária em que ambas instâncias estão mergulhadas, histórica e presentemente informada, em escala global, pelo capitalismo que ganha contornos singulares em cada país, tornando mais exigente a busca de soluções.

Assim, mesmo a perspectiva européia de educação intercultural com a intenção de superar o multiculturalismo esbarra em obstáculos de várias ordens que somente a reflexão teórica radical, rigorosa e atenta será capaz de contornar. Recordando a idéia apresentada no início do texto que explica seu título, a proposta de educação intercultural na Europa ainda que seja pensada a partir do pressuposto de uma dinâmica de relações sociais, mas abstratas, ao desconsiderar os contornos da sociedade capitalista atual, incorre no mesmo equívoco que se imputa a outrem: limitase a constatar o estado de parceiros culturalmente diferentes em conflito. Sem que nessa proposta seja aprofundada a compreensão das razões históricas que determinam esse conflito e sendo desconsiderado o seu caráter desigual, torna-se difícil recuperar, em pensamento, o processo que institui essa situação, inviabilizando teórica e praticamente as propostas de intervenção.

\section{Referências bibliográficas}

ABDALLAH-PRETCEILLE, Martine. L'école face au défi pluraliste. In: CAMILLERI, Carmel, COHEN-EMERIQUE, Margalit (Org.). Chocs de cultures : concepts et enjeux pratiques de l'interculturel. Paris : L'Harmattan, 1989. p. 225-245.

Pédagogie interculturelle : bilan et perspectives. In: COLLOQUE NATIONAL DE TOULOSE. Actes L'interculturel en éducation et en sciences humaines. Toulouse : ERESI, 1985. p. 25-32.

BARTH, F. Les groupes ethiniques et leurs frontières. In: POUTIGNAT, Ph., STREIFF-FENART, Joceline. Théories de l'ethinicité. Paris : PUF, 1995. p. 203-249.

BARTHES, Roland. Mitologias. São Paulo : Difel, 1982.

BRASIL. Lei n ${ }^{\circ}$ 9.394, de 20 de dezembro de 1996. Estabelece as diretrizes e bases da educação nacional. Diário Oficial, Brasília, 23 dez. 1996. p. 27833-27841.

CAMILLERI, Carmel. La culture et l'identité culturelle : champ notionnel et devenir. In: CAMILLERI, Carmel, COHEN-EMERIQUE, Margalit (Org.). Chocs de cultures : concepts et enjeux pratiques de l'interculturel. Paris : L'Harmattan, 1989. p. 21-73.

CAMILLERI, Carmel, COHEN-EMERIQUE, Margalit (Org.). Chocs de cultures : concepts et enjeux pratiques de l'interculturel. Paris : L'Harmattan, 1989.

COHEN-EMERIQUE, Margalit. La formation des enseignants : pour une approche interculturelle. Bruxelles, 1994. Intervention au colloque organisé par la Communauté française.

. Travailleurs sociaux et migrants la reconnaissance identitaire dans le processus d'aide. In: CAMILLERI, Carmel, COHEN-EMERIQUE, Margalit (Org.). Chocs de cultures: concepts et enjeux pratiques de l'interculturel. Paris : L'Harmattan, 1989. p. 77-115.

COMMUNAUTE ECONOMIQUE EUROPEENNE (CEE). Directive du Conseil du 25 juillet 1977 (77/486/CEE). Journal officiel des Communautés européennes, Bruxelles, 6/8/ $77, n^{\circ}$ L 199/32-3. Visand à la scolarisation des enfants des travailleurs migrants. (sic.) 
CONSEIL DE L'EUROPE. L'éducation des enfants migrants : recueil d'informations sur les opérations d'éducation interculturelle en Europe. Strasbourg, 1983.

DAYRELL, Juarez (Org.). Múltiplos olhares sobre educação e cultura. Belo Horizonte : UFMG, 1996.

GAUDIER, Jean-Pierre. Faut-il respecter la culture des autres? a propos de l'idéologie interculturaliste et du corps enseignant. Tribune Imigrée, Bruxelles, n. 32, p. 39, mars 1990.

HENRY-LORCERIE, Françoise. Ecole e pluralité : trois entrées dans la bibliographie. In: LIAUZU, Claude. Immigration et école : la pluralité culturelle. Paris : IREMAN, 1989. p. 21-30.

HOBSBAWN, Eric. Era dos extremos : o breve século XX, 1914-1991. Tradução de Marcos Santarrita. 2. ed. São Paulo : Companhia das Letras, 1995. Revisão técnica Maria Célia Paoli.

LEURIN, Marcel. L'éducation interculturelle : pourquoi? comment? : analyse et diffusion des travaux du groupe de projet $n^{\circ} 7$ du Conseil de l'Europe, octobre 1987. In: SÉMINAIRE INTERNATIONAL. L'éducation et la formation en Europa. Frascati, 1987.

LIAUZU, Claude. Plurarité et lien social. In: culturelle. Paris : IREMAN, 1989. p. 9-30. . Immigration et école : la pluralité

MAUVIEL, Maurice. Qu'appelle t-on études interculturelles en sciences humanines et en sciences de l'éducation? Esquisse d'un état de la question. In: COLLOQUE NATIONAL DE TOULOSE. Actes L'interculturel en éducation et en sciences humaines. Toulouse : ERESI, 1985. p. 3-23.

MUNANGA, Kabengele (Org.). Estratégias e políticas de combate à discriminação racial. São Paulo : EDUSP, Estação Ciência, 1996.

POPKEWITZ, Thomas S. Cultura, pedagogia e poder. Teoria \& Educação, Porto Alegre, n. 5, p. 91-106, 1992.

REY, Micheline. Lignes de force d'une éducation interculturelle. In: CONSEIL DE L'EUROPE. L'éducation des enfants migrants : recueil d'informations sur les opérations d'éducation interculturelle en Europe. Strasbourg, 1983. p. 203-208.

SANTOMÉ, Jurjo Torres. Política educativa, multiculturalismo y prácticas culturales democráticas en las aulas. In: REUNIÃO DA ANPED, 19, Caxambú, 1996. Anais... Caxambu : Anped, 1996.

SCHWARCZ, Lilia Moritz, QUEIROZ, Renato da Silva (Org.). Raça e diversdade. São Paulo : EDUSP, Estação Ciência, 1996.

SILVA, Luiz Eron da, AZEVEDO, José Clóvis, SANTOS, Edmilson. Novos mapas culturais, novas perspectivas educacionais. Porto Alegre : Ed. Sulina, 1996.

SILVA, Tomaz Tadeu da (Org.). Alienígenas na sala de aula : uma introdução aos estudos culturais em educação. Petrópolis : Vozes, 1995.

SILVA, Tomaz Tadeu da, MOREIRA, Antonio Flávio (Org.). Territórios contestados : o currículo e os novos mapas políticos culturais. Petrópolis : Vozes, 1995.

THORSTENSEN, Vera. Comunidade Européia : a construção de uma potência econômica. São Paulo : Brasiliense, 1992.

UNIÃO EUROPÉIA. Compilação dos Tratados. Luxemburgo : Serviço das Publicações Oficiais das Comunidades Européias, 1993. v. 1, t. 1. 
VALENTE, Ana Lúcia E. F. Economia sem fronteiras e processo educacional reativo : a reivindicação da diferença na Europa unificada. Campo Grande, 1993. Projeto de pós-doutorado.

Proposta metodológica de combate ao racismo nas escolas. Cadernos de Pesquisa, São Paulo, n. 93, p. 40-50, maio 1995.

Ser negro no Brasil hoje. 15. ed. rev. e ampl. São Paulo : Moderna, 1996a.

Em terreno escorregadio : educação intercultural na capital da União Européia - ensaio de Antropologia da Educação. Louvain-la-Neuve, maio/junho, 1996b. Relatório de pesquisa.

VERBUNDT, Gilles. Les associations ethiniques come lieux d'intégration sociale. In: CAMILLERI, Carmel, COHEN-EMERIQUE, Margalit (Org.). Chocs de cultures : concepts et enjeux pratiques de l'interculturel. Paris : L'Harmattan, 1989. p. 135-163.

VERNE, Etienne. Les politiques d'éducation multiculturelle : analyse critique. In: OCDE. CERI. L'éducation multiculturelle. Paris : OCDE, 1987. p. 27-65.

Recebido em 28 de novembro de 1997.

Ana Lúcia Eduardo Farah Valente, doutora em Antropologia Social pela Universidade de São Paulo (USP), é professora adjunta da Universidade Federal de Mato Grosso do Sul, atuando no curso de Mestrado em Educação.

\section{Abstract}

In general terms, this text presents and comments on some aspects present in the construction of the European Educational Proposal which aims at surpassing the American multicultural perspective through the implementation of intercultural education. The text aims at furnishing subsidiary material in order to apprehend the singular character of the brazilian case, within a comparative perspective, as well as elements for the debate and problematization of the "new cultural maps" currently being established, objects of recent interest in the question of cultural differences in academic studies and proposals for its incorporation in scholl curriculum. However, discussions do not end with studies on school curriculum; they go further on to an understanding of the methodological perspectives directing the proposals being made, given the fact that these are diversified expressions of the attempt, in theory and practice, to dominate the explicit and implicit mechanisms configuring the tendency towards globalisation inherent in capitalism, in this current moment of crisis that releases heterogeneous reactive manifestations in the politico-cultural area.

Key-Words: intercultural education, european education, american multiculturalism. 